Article

\title{
The Study of Characteristic Environmental Sites Affected by Diverse Sources of Mineral Matter Using Compositional Data Analysis
}

\author{
Antonio Speranza *, Rosa Caggiano, Giulia Pavese and Vito Summa \\ IMAA, Istituto di Metodologie per l'Analisi Ambientale, CNR, 85050 Tito Scalo, PZ, Italy; \\ rosa.caggiano@imaa.cnr.it (R.C.); giulia.pavese@imaa.cnr.it (G.P.); vito.summa@imaa.cnr.it (V.S.) \\ * Correspondence: antonio.speranza@imaa.cnr.it; Tel.: +39-0971-427-230
}

Received: 13 March 2018; Accepted: 3 May 2018; Published: 7 May 2018

\begin{abstract}
Compositional data analysis was applied on mineral element concentrations (i.e., $\mathrm{Al}, \mathrm{Ti}, \mathrm{Si}$, $\mathrm{Ca}, \mathrm{Mg}, \mathrm{Fe}, \mathrm{Sr}$ ) content in $\mathrm{PM}_{10}, \mathrm{PM}_{2.5}$ and $\mathrm{PM}_{1}$ simultaneous measurements at three characteristic environmental sites: kerbside, background and rural site. Different possible sources of mineral trace elements affecting the PM in the considered sites were highlighted. Particularly, results show that compositional data analysis allows for the assessment of chemical/physical differences between mineral element concentrations of PM. These differences can be associated with both different kinds of involved mineral sources and different mechanisms of accumulation/dispersion of PM at the considered sites.
\end{abstract}

Keywords: particulate matter; simultaneous measurements; mineral elements; compositional data analysis

\section{Introduction}

Particulate matter (PM) is a mixture of particles present in the air with different masses, sizes, shapes, surface areas, characterized by many chemical elements and compounds. The interest in PM has widely increased in the last several decades owing to its detrimental effect on the public health and the environment [1-3]. PM particles when inhaled can be deposited within the respiratory system and can act as a universal carrier of a wide variety of chemical substances potentially toxic [4,5]. It is well known that acute and chronic exposure to PM is associated with adverse effects on the cardiovascular and respiratory system [6]. PM is also associated with air quality and visibility degradation as well as to Earth's climate change [7,8]. PM particles can affect solar radiation as it passes through the atmosphere due to their properties of scattering and absorptions of light as well as being able to alter the radiative properties of weather clouds and their lifetime determining a possible effect on incoming and outgoing solar radiation and on the overall energy balance of Earth [9-11].

In the light of aforesaid significance of PM, effective mitigation strategies of PM levels into the air, to protect the environment and the public health, require a detailed assessment of the possible PM emission sources in relation to its chemical composition [12]. In the European context, selected groups of chemical elements and compounds have been linked to specific natural and anthropogenic sources of PM such as $\mathrm{Al}, \mathrm{Si}, \mathrm{Ca}, \mathrm{Fe}, \mathrm{Ti}, \mathrm{Mg}$ and $\mathrm{Sr}$ to crustal and mineral matter and African dust, $\mathrm{Na}$, $\mathrm{Cl}$ and $\mathrm{Mg}$ to marine sources and sea spray, $\mathrm{V}$ and $\mathrm{Ni}$ to fuel-oil combustion, $\mathrm{SO}_{4}{ }^{2-}, \mathrm{NO}_{3}{ }^{-}$and $\mathrm{NH}_{4}{ }^{+}$ to secondary aerosol and long range transport [13]. However, the identification of an element or a group of elements that can unequivocally be attributed to specific natural or anthropogenic sources of mineral matter has proven to be problematic. Sources of mineral matter including desert, crustal dust due to road traffic and farming activities as well as dust due to demolition and construction 
activities can have in common the same range of chemical elements. Up to today, the identification and characterization of different sources of mineral matter contributing to atmospheric PM mixture remains inadequate and requires still further research as pointed out in the literature [13-15].

In the meanwhile, several authors have focused their studies on the simultaneous measurements of PM size fractions: $\mathrm{PM}_{10}, \mathrm{PM}_{2.5}$ and $\mathrm{PM}_{1}$ (i.e., particles with aerodynamic diameters below 10, 2.5 and $1 \mu \mathrm{m}$, respectively). Due to the fact that PM particles with different sizes are emitted into the air from different sources and have different physical and chemical characteristics, the assessment of the PM size fractions can provide with important data on the process of formation of the PM and the identification of its sources. The PM coarse size fraction (i.e., particles with aerodynamic diameters between 2.5 and $10 \mu \mathrm{m}$ ) can mainly originate from both natural and anthropogenic sources including desert dust, volcanic eruptions, sea spray, fugitive dust from paved and unpaved dusty roads, demolition and construction activities [16-18]. The fine size fraction $\left(\mathrm{PM}_{2.5}\right)$ and submicron size fraction $\left(\mathrm{PM}_{1}\right)$ can mainly originate from anthropogenic sources such as industrial activities, road traffic, different kinds of combustion processes and secondary particles generated in the atmosphere [19-21]. The simultaneous measurements of $\mathrm{PM}_{10}, \mathrm{PM}_{2.5}$ and $\mathrm{PM}_{1}$ have been carried out in a range of different environmental sites such as traffic point [22], urban traffic and suburban background sites [23], Nordic background site and wild fire episodes [24], urban background and rural sites [25,26], industrial sites [27,28], superstation site [29], urban areas and surroundings sites [30] and suburban sites and regional background [31]. Further environmental investigations on size-segregate PM simultaneous measurements were reported elsewhere [32,33].

This preliminary study investigates the application of compositional data analysis to mineral element concentrations of size-segregated PM simultaneous measurements. Compositional data consist of vectors whose components represent proportions or percentages of a certain quantity. The characteristic of these vectors is that the sum of their components is a constant, equal to 1 for proportions, 100 for percentages or some other constant c. These compositional data may refer to mineral composition of rocks, sediments, pollutant compositions, mixture of gases, water composition, etc. Compositional data with appropriate statistical tools have been used for interpreting environmental data as well as for characterizing processes acting in the environment. Statistical analysis of compositional data began with Aitchison [34,35] and since then has undergone several developments. Today, a consolidated statistical technique is considered [36-40].

This study is based on mineral element concentrations of $\mathrm{PM}_{10} \mathrm{PM}_{2.5}$ and $\mathrm{PM}_{1}$ simultaneous measurements sampled in three characteristic sites (i.e., kerbside, background and rural site) possibly affected by diverse sources of mineral matter [41]. The relevance of mineral element concentrations of PM at kerbside site was taken into consideration. Mineral element concentrations of PM from the kerbside were compared with that from background and rural sites [42,43].

The main objective of this preliminary study is to evaluate the essential differences between the two patterns of variability of kerbside and background site dataset as well as between the two patterns of variability of kerbside and rural site dataset. These comparisons aim to highlight the underlying processes that influence the mineral element concentrations of PM of the considered environmental sites. The present study shows that the PM of the investigated environmental sites can be affected from different sources of mineral matter. Moreover, mechanisms of accumulation and/or dispersion of mineral matter can be observed.

\section{Materials and Methods}

Mineral elements concentrations of $\mathrm{PM}_{10}, \mathrm{PM}_{2.5}$ and $\mathrm{PM}_{1}$ simultaneous measurements as reported in literature have been considered and they refer to three characteristics monitored environmental sites namely rural, background and kerbside site. The kerbside site was placed close to a trafficked road and at the side of a street canyon, the background site was placed in a residential area close to school building and the rural site was located away from direct emission sources and in a site surrounded by fields. The measurements were conducted in winter (January-February). The samples of PM were 
collected using a rotating drum impactor. The elements on the collected samples were analyzed using a synchrotron radiation-induced $X$-ray fluorescence spectrometry [41]. The mineral elements considered were $\mathrm{Al}, \mathrm{Ti}, \mathrm{Si}, \mathrm{Ca}, \mathrm{Mg}$, Fe, Sr. These mineral elements were mostly and commonly interpreted as related to mineral matter [13]. In this section, the methods used for the compositional data analysis are summarized.

\subsection{Compositional Data and Sample Space}

Compositional data are vectors whose components are positive numbers and they sum to a constant, usually 1 or 100 . The sample space of a compositional observation $\mathbf{x}$ with three components is the unit simplex:

$$
S_{c}^{3}=\left\{\mathbf{x}=\left(x_{1}, x_{2}, x_{3}\right) \mid x_{j}>0, j=1,2,3 ; x_{1}+x_{2}+x_{3}=c\right\}
$$

The simultaneous measurements $\mathrm{PM}_{10}, \mathrm{PM}_{2.5}$ and $\mathrm{PM}_{1}$ can be decomposed in their relative fractions as coarse (see Equation (2)), intermodal (see Equation (3)) and submicron, $\mathrm{PM}_{1}, \mathrm{mass}$ concentration [44-46]:

$$
\begin{gathered}
P M_{10-2.5}=P M_{10}-P M_{2.5} \\
P M_{2.5-1}=P M_{2.5}-P M_{1}
\end{gathered}
$$

These fractions can be converted into compositions based on proportions by weight $[40,47]$ :

$$
\mathbf{x}=\left(\frac{P M_{10-2.5}}{P M_{10}}, \frac{P M_{2.5-1}}{P M_{10}}, \frac{P M_{1}}{P M_{10}}\right) \% .
$$

The compositional variables of this vector, $\mathbf{x}$, are nonnegative and they sum to a constant $c=$ 100 (see Equation (1)). The compositional data related to simultaneous sampling of $\mathrm{PM}_{10}, \mathrm{PM}_{2.5}$ and $\mathrm{PM}_{1}$ of various mineral elements can be cast into the form of a matrix $\mathbf{x}$, with $i$ rows representing the mineral elements and $j$ columns representing the coarse, intermodal and submicron size fractions. This matrix, a three part compositional dataset, takes into account the mineral element concentrations of PM with respect to its coarse, intermodal, and submicron, size fraction in \%.

The following matrix for the simultaneous measurements $\mathrm{PM}_{10}, \mathrm{PM}_{2.5}$ and $\mathrm{PM}_{1}$ of the elements $\mathrm{Al}, \mathrm{Ti}, \mathrm{Si}, \mathrm{Ca}, \mathrm{Mg}$, Fe, Sr was considered in each characteristic environmental sites (i.e., rural, kerbside and background):

$$
\mathbf{x}=\left\{\begin{array}{cll}
\left(\frac{P M_{10-2.5}}{P M_{10}}\right)_{A l} & \left(\frac{P M_{2.5-1}}{P M_{10}}\right)_{A l} & \left(\frac{P M_{1}}{P M_{10}}\right)_{A l} \\
\left(\frac{P M_{10-2.5}}{P M_{10}}\right)_{T i} & \left(\frac{P M_{2.5-1}}{P M_{10}}\right)_{T i} & \left(\frac{P M_{1}}{P M_{10}}\right)_{T i} \\
\left(\frac{P M_{10-2.5}}{P M_{10}}\right)_{S i} & \left(\frac{P M_{2.5-1}}{P M_{10}}\right)_{S i} & \left(\frac{P M_{1}}{P M_{10}}\right)_{S i} \\
\left(\frac{P M_{10-2.5}}{P M_{10}}\right)_{C a} & \left(\frac{P M_{2.5-1}}{P M_{10}}\right)_{C a} & \left(\frac{P M_{1}}{P M_{10}}\right)_{C a} \\
\left(\frac{P M_{10-2.5}}{P M_{10}}\right)_{M g} & \left(\frac{P M_{2.5-1}}{P M_{10}}\right)_{M g} & \left(\frac{P M_{1}}{P M_{10}}\right)_{M g} \\
\left(\frac{P M_{10-2.5}}{P M_{10}}\right)_{F e} & \left(\frac{P M_{2.5-1}}{P M_{10}}\right)_{F e} & \left(\frac{P M_{1}}{P M_{10}}\right)_{F e} \\
\left(\frac{P M_{10-2.5}}{P M_{10}}\right)_{S r} & \left(\frac{P M_{2.5-1}}{P M_{10}}\right)_{S r} & \left(\frac{P M_{1}}{P M_{10}}\right)_{S r}
\end{array}\right\} \% .
$$

\subsection{Transformation of Compositional Data}

Compositional data in Equation (4) are constrained to a constant sum. The statistical analysis of compositional data requires an approach based on log-ratios transformation. Using this transformation, 
a composition is represented as a real vector. The compositional data are transformed into coordinates using ilr (isometric log-ratio) transformations [48,49] (see Equation (6)):

$$
\operatorname{ilr}(\mathbf{x})=\left(\frac{1}{\sqrt{2}} \ln \left(\frac{P M_{10-2.5}}{P M_{2.5-1}}\right), \frac{1}{\sqrt{6}} \ln \left(\frac{P M_{10-2.5} P M_{2.5-1}}{P M_{1}^{2}}\right)\right)=\left(i l r_{1}, i l r_{2}\right)=\mathbf{y} .
$$

The following matrix for $\mathrm{PM}_{10}, \mathrm{PM}_{2.5}$ and $\mathrm{PM}_{1}$ simultaneous measurements of the elements $\mathrm{Al}$, $\mathrm{Ti}, \mathrm{Si}, \mathrm{Ca}, \mathrm{Mg}$, Fe, $\mathrm{Sr}$ was considered in each characteristic environmental sites (i.e., rural, kerbside and background) in terms of log-ratios:

$$
Y=\left\{\begin{array}{cc}
i l r_{1 A l} & i l r_{2 A l} \\
i l r_{1 T i} & i l r_{2 T i} \\
i l r_{1 S i} & i l r_{2 S i} \\
i l r_{1 C a} & i l r_{2 C a} \\
i l r_{1 M g} & i l r_{2 M g} \\
i l r_{1 F e} & i l r_{2 F e} \\
i l r_{1 S r} & i l r_{2 S r}
\end{array}\right\} .
$$

The isometric coordinates $i l r_{1}$ and $i l r_{2}$ can be inverse transformed by:

$$
\mathbf{x}=C\left(\exp \left(\frac{i l r_{2}}{\sqrt{6}}+\frac{i l r_{1}}{\sqrt{2}}\right), \quad \exp \left(\frac{i l r_{2}}{\sqrt{6}}-\frac{i l r_{1}}{\sqrt{2}}\right), \quad \exp \left(-\frac{2 i l r_{2}}{\sqrt{6}}\right)\right),
$$

where $C$ is the closure operation for a vector $\mathbf{x}$ defined as below in Equation (9). This operation divides each component of the vector $\mathbf{x}$ by the sum of its components, hence scaling the vector to the constant $c$ :

$$
C(\mathbf{x})=\left(\frac{c x_{1}}{x_{1}+x_{2}+x_{3}}, \frac{c x_{2}}{x_{1}+x_{2}+x_{3}}, \frac{c x_{3}}{x_{1}+x_{2}+x_{3}}\right) .
$$

\subsection{Triangular Diagram Representation, Centering and Rescaling Technique}

The compositional datasets, their centres and confidence regions can be represented using a triangular diagram. The data is displayed by Graham and Midgley [50]. Calculations were produced using Coda Pack Software [51] and R Software [52]. Compositional data can be centered using the perturbation operator of the simplex [35].

The perturbation operation is defined as the perturbation $\mathbf{p}$ applied to a composition $\mathbf{x}$ that produces the composition $\mathbf{v}$ :

$$
\mathbf{v}=\mathbf{p} \oplus \mathbf{x}=\left(p_{1}, p_{2}, p_{3}\right) \oplus\left(x_{1}, x_{2}, x_{3}\right)=C\left(p_{1} x_{1}, p_{2} x_{2}, p_{3} x_{3}\right),
$$

with $\mathbf{v}, \mathbf{p}$ and $\mathbf{x}$ vectors in $S^{3}$; $C$ is the closure operation (see Equation (9)).

Perturbing a vector $\mathbf{x}$ by its inverse (see Equation (11)), it is possible to locate any composition in the baricenter of the triangular diagram:

$$
\mathbf{x}^{-1}=\left(x_{1}^{-1}, \quad x_{2}^{-1}, x_{3}^{-1}\right) .
$$

Likewise, it is possible to centre a compositional dataset of size $n$ :

$$
\left\{\left(x_{i 1}, x_{i 2} \quad x_{i 3}\right), i=1,2, \ldots, n\right\},
$$


using the inverse of its centre $\mathbf{g}^{-1}$ defined as Equation (13) [53,54]:

$$
\mathbf{g}=C\left(\begin{array}{lll}
g_{1}, & g_{2}, & g_{3}
\end{array}\right) \text { where } g_{j}=\left(\prod_{i=1}^{n} x_{i, j}\right)^{\frac{1}{n}}, j=1,2,3
$$

The centering and rescaling of the compositional data allows for better visualizing compositions close to the boundary of the triangular diagram preserving straight lines of the grid as well as statistical properties [55].

\subsection{Perturbation Difference}

The perturbation difference is defined as the perturbation $\mathbf{p}$ to which a change can be attributed from a composition $\mathbf{x}$ to a composition $\mathbf{y}$, whatever the processes involved, (see Equation (14))

$$
\mathbf{p}=\mathbf{x z}=\left(x_{1}, x_{2}, x_{3}\right)\left(z_{1}, z_{2}, z_{3}\right)=C\left(\frac{x_{1}}{z_{1}}, \frac{x_{2}}{z_{2}}, \frac{x_{3}}{z_{3}}\right),
$$

with $\mathbf{p}, \mathbf{x}$ and $\mathbf{z}$ vectors in $S^{3}{ }_{c}$ [56]; $C$ is the closure operation (see Equation (9)).

\subsection{Testing Hypothesis of Multivariare Normal Distribution}

The multivariate normal distribution is a generalization of the normal distribution to higher dimensions. The test hypothesis on multivariate normal distribution of the compositional dataset relating to rural, kerbside and background (see Equation (5)) is needed before performing the test hypothesis about center and covariance structure. The test used for multivariate normality is the Anderson-Darling, Cramer-von Mises and Watson of log-ratios transformed dataset (see Equation (7)) [35,36].

\subsection{Testing Hypothesis about the Center and the Covariance Structure}

In order to evaluate whether there are real differences between two datasets in the center, in the covariance structure, or in both, a test hypothesis about center and covariance structure was performed. The test is applied to log-ratios transformed dataset (see Equation (7)). The methods are described in [35] (pp. 153-158), [36]. The PM size fractions and its chemical composition provide with important data on the process of formation of the PM and the identification of its sources [16-21]. The center and the covariance structure of a compositional dataset $\mathbf{x}$ as derived from PM simultaneous measurements are linked to the chemical composition and distribution of the elements within coarse, intermodal and submicron size fraction. The test hypothesis about center and covariance structure allows for the statistical evaluation of differences between the chemical composition and the size distribution between two datasets. Therefore, the results of the above test provide information about the diverse PM sources and its formation processes between two considered datasets.

\section{Results and Discussion}

The difference between the mineral element concentrations of PM relating to background and kerbside site was evaluated comparing their compositional datasets. Figure 1a shows the three part compositional dataset of two characteristic monitored environmental sites such as background and kerbside after the application of the centering and rescaling technique. The three part compositional dataset of background and kerbside are displayed with high values of coarse size fraction above $55 \%$ and with low values of intermodal and submicron size fraction, which are below about $35 \%$ and $12 \%$, respectively. The coarse size fraction is the dominant component in mineral tracers [57]. The application of the centering and rescaling technique allows for a better visualization of the data despite the low values of intermodal and submicron size fraction. The three compositional datasets 
and their respective centres are closely displayed. Thus, in order to confirm or reject the hypothesis about the occurrence of two distinct sets, a statistical analysis is performed [57].

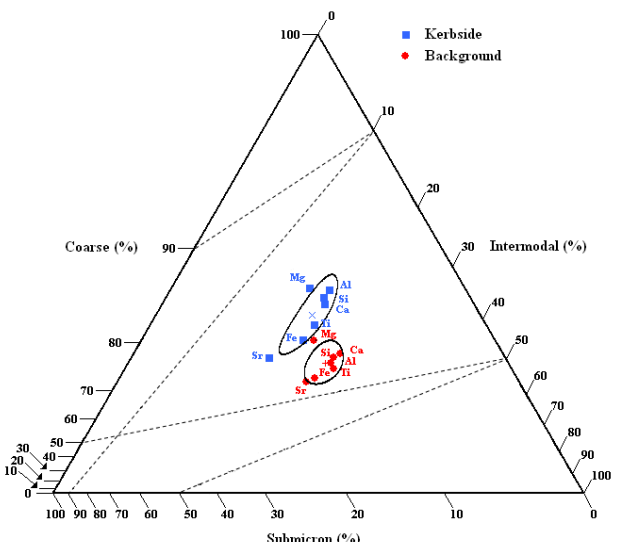

(a)

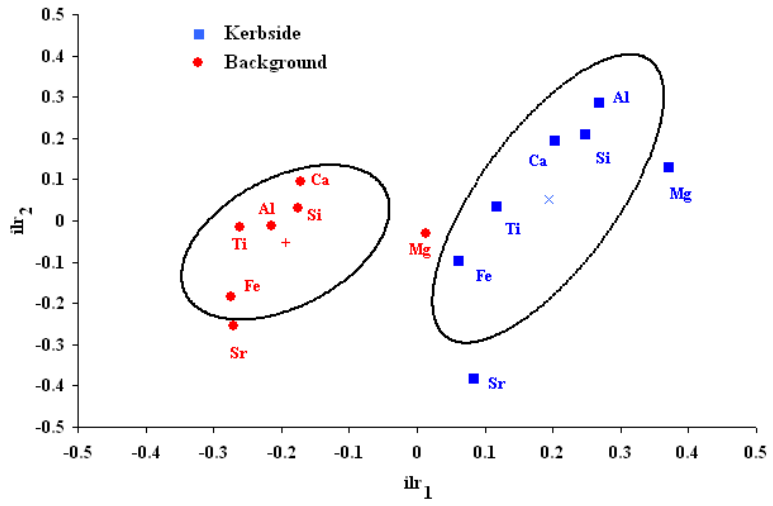

(b)

Figure 1. The mineral elements $\mathrm{Al}, \mathrm{Ti}, \mathrm{Si}, \mathrm{Ca}, \mathrm{Mg}$, $\mathrm{Fe}, \mathrm{Sr}$; (a) distribution of the compositional data plotted using Equation (4) and after perturbation $\mathbf{g}^{-1}=(8.53,20.84,70.63)$. The centre for background site is at $\mathbf{g}=(59.31,31.93,8.76)$ denoted with + , and the centre for kerbside site is at $\mathbf{g}=(70.91,22.08$, 7.01) denoted with $\times$; (b) distribution of the data as for isometric log-ratios (see Equation (6)) after perturbation. The centre for both datasets is at $\left(\mathrm{ilr}_{1}, \mathrm{ilr}_{2}\right)=(0,0)$, the centre for background site is at $\left(\mathrm{ilr}_{1}, \mathrm{ilr}_{2}\right)=(-0.19,-0.05)$ denoted with + , and the centre for kerbside site is at $\left(\mathrm{ilr}_{1}, \mathrm{ilr}_{2}\right)=(0.19,0.05)$ denoted with $\times$. The continuous lines are the confidence regions $(1-\alpha) 100 \%, \alpha=0.05$.

The two datasets of background and kerbside are tested for multivariate normality. The numerical results are reported in Table 1 and are compared with critical values reported by Stephens [36,58]. The bivariate angle test shows that the hypothesis of normality can be accepted for both background and kerbside site with a significance level greater than $10 \%$.

Table 1. Tests on multivariate normality for the datasets of rural, kerbside and background sites.

\begin{tabular}{lccc}
\hline Sites & Anderson-Darling & Cramer-von Mises & Watson \\
\hline Rural & & & \\
ilr $_{1}$ marginal distribution & 0.6727 & 0.1260 & 0.1244 \\
ilr $_{2}$ marginal distribution & 0.8657 & 0.1405 & 0.1377 \\
Bivariate angle test & 1.7077 & 0.2927 & 0.0608 \\
statistics & & & \\
\hline Kerbside & & & 0.0419 \\
ilr ${ }_{1}$ marginal distribution & 0.2821 & 0.0420 & 0.0633 \\
ilr $_{2}$ marginal distribution & 0.4277 & 0.0646 & 0.1293 \\
Bivariate angle test & 1.6273 & 0.3314 & \\
statistics & & & 0.1004 \\
\hline Background & & & 0.0944 \\
ilr & & 0.1024 & 0.0510 \\
ilr marginal distribution & 0.6848 & 0.0951 & \\
Bivariate angle test & 0.4985 & 0.0804 & \\
statistics & 0.7345 & & \\
\hline
\end{tabular}

The marginal test shows that the hypothesis of normality can be accepted for the kerbside site, referring to both $i r_{1}$ and $i r_{2}$, with a significance level greater than $10 \%$. The marginal test shows that the hypothesis of normality can be accepted for the background site with a significance level greater than $5 \%$ and $10 \%$ for $i r_{1}$ and $i l r_{2}$, respectively. Therefore, for each dataset, the hypothesis of 
multivariate normality cannot be rejected. Thus, the datasets of kerbside and background site are tested for hypothesis of equality in their centres and covariance structures [35] (p. 153), [36]. The results are reported in Table 2 . The test value for the datasets related to kerbside and background site is below the critical value for the considered hypothesis of inequality of centres, equivalent to $\mu_{1} \neq \mu_{2}$, and equality of covariance structure, equivalent to $\Sigma_{1}=\sum_{2}$, thus this last hypothesis cannot be rejected. The inequality between the two centres indicates that the mineral element distribution differs for the two datasets. Mineral elements are more abundant in the coarse and intermodal size fraction in the dataset related to kerbside. Thus, it can be assumed that at the kerbside site there are mechanisms that promote the accumulation of elements in the coarser fractions.

Table 2. Test about the centres and the covariance structures for kerbside and background site.

\begin{tabular}{cllll}
\hline \multicolumn{1}{c}{ Hypothesis } & Test Value & $\chi^{2}$ Critical Value $(\boldsymbol{\alpha}=\mathbf{0 . 0 5})$ & Degrees of Freedom & Significance \\
\hline$\mu_{1}=\mu_{2}, \sum_{1}=\sum_{2}$ & 25.57 & 11.07 & 5 & 0.0001 \\
$\mu_{1} \neq \mu_{2}, \sum_{1}=\sum_{2}$ & 2.70 & 7.81 & 3 & 0.4403 \\
$\mu_{1}=\mu_{2}, \sum_{1} \neq \sum_{2}$ & - & 5.99 & 2 & - \\
\hline
\end{tabular}

However, the equality between the two covariance structures suggests that the datasets related to kerbside and background site cannot be regarded as clearly distinct for chemical composition (see Figure 2b).

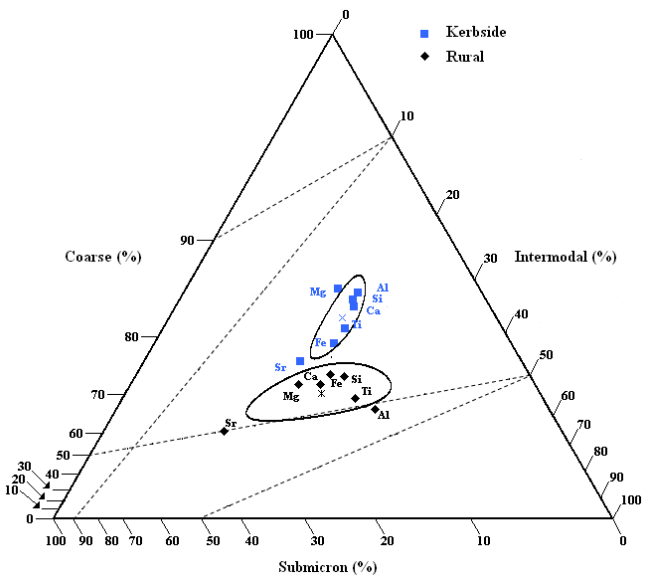

(a)

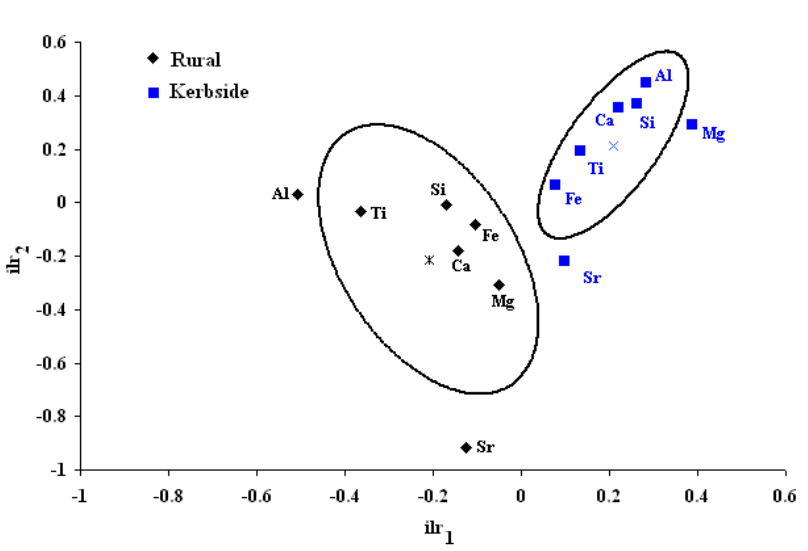

(b)

Figure 2. The mineral elements $\mathrm{Al}, \mathrm{Ti}, \mathrm{Si}, \mathrm{Ca}, \mathrm{Mg}$, $\mathrm{Fe}, \mathrm{Sr}$; (a) distribution of the compositional data plotted using Equation (4) and after perturbation after perturbation $\mathbf{g}^{-1}=(9.9,23.63,66.47)$. The centre for the rural site is at $\mathbf{g}=(55.94,31.52,12.54)$ denoted with $*$, and the centre for kerbside site is at $\mathbf{g}=(70.91,22.08,7.01)$ denoted with $\times ;(\mathbf{b})$ distribution of the data as for isometric log-ratios (see Equation (6)) after perturbation. The centre for both dataset is at $\left(i \operatorname{lr}_{1}, i \operatorname{ll}_{2}\right)=(0,0)$, the centre for the rural site is at $\left(\mathrm{ilr}_{1}, \mathrm{ilr}_{2}\right)=(-0.21,-0.21)$ denoted with *, and the centre for kerbside site is at $\left(\mathrm{ilr}_{1}, \mathrm{ilr}_{2}\right)=$ $(0.21,0.21)$ denoted with $\times$. The continuous lines are the confidence regions $(1-\alpha) 100 \%, \alpha=0.05$.

These results can be interpreted so that kerbside and background site are characterized by similar sources of mineral matter for the set of considered mineral elements.

In order to evaluate the nature of the difference between the element concentrations of PM for kerbside and background site, the perturbation difference is calculated between the perturbation centres related to kerbside and background site compositional dataset [59]. The perturbation centre for background site is $(59.31,31.93,8.77)_{\text {(background) }}$. The perturbation centre for kerbside site is $(70.91$, $22.08,7.01)_{\text {(kerbside) }}$. The perturbation difference is $(44.51,25.75,29.74)_{\text {(kerbside)-(background) }}$ suggesting that the relative difference between these two sites is mainly in the coarse size fraction. 
The simultaneous PM measurements at a kerbside site refer to a very busy road with a street canyon feature. Thus, it can be supposed that, at the kerbside, the effect of large traffic volumes combined with possibly narrow streets and multi-floor institutional and commercial building can determine a local characteristic accumulation/dispersion condition (e.g., street canyon environment) [60]. These conditions may lead to higher tracer concentrations of the coarse size fraction.

Likewise, the difference between the mineral elements concentrations of PM relating to kerbside and rural site was evaluated comparing their compositional datasets. Figure 2a shows the three part compositional dataset of two characteristic monitored environmental sites such as kerbside and rural site after the application of the centering and rescaling technique. The three part compositional data of kerbside and rural site are displayed with high values of coarse size fraction above approximately $50 \%$ and with low values of intermodal and submicron size fraction, which are below about $40 \%$ and $25 \%$, respectively. The coarse size fraction is the dominant component. The application of the centering and rescaling technique allows for a better visualization of the data despite the low values of intermodal and submicron size fraction. The compositional datasets of kerbside and rural as well as their respective centres are closely displayed. As above, in order to confirm or reject the hypothesis about the occurrence of two distinct sets, a statistical analysis is performed. The dataset of rural site is tested for multivariate normality. The numerical results are reported in Table 1 and they are compared with critical values. The bivariate angle test shows that the hypothesis of normality can be accepted with a significance level greater than $10 \%$. The marginal test shows that the hypothesis of normality can be accepted for the rural site with a significance level greater than $5 \%$ and $2.5 \%$ for $i \mathrm{lr}_{1}$ and $\mathrm{ilr}_{2}$, respectively. Therefore, the hypothesis of multivariate normality cannot be rejected. Thus, the datasets of kerbside and rural site are tested for hypothesis of equality in their centres and covariance structures. The results are reported in Table 3. The test values for the datasets related to kerbside and rural site are above the critical ones for each considered hypothesis, thus the equality of centres, equivalent to $\mu_{1}$ $=\mu_{2}$, of covariance structures, equivalent to $\sum_{1}=\sum_{2}$, or of both has to be rejected. The two datasets related to kerbside and rural site have to be regarded as clearly distinct for chemical composition and mineral element distributions (see Figure 2b).

Table 3. Test about the centres and the covariance structures for kerbside and rural site.

\begin{tabular}{lllll}
\hline \multicolumn{1}{c}{ Hypothesis } & Test Value & $\chi^{\mathbf{2}}$ Critical Value $(\boldsymbol{\alpha}=\mathbf{0 . 0 5})$ & Degrees of Freedom & Significance \\
\hline$\mu_{1}=\mu_{2}, \sum_{1}=\sum_{2}$ & 27.26 & 11.07 & 5 & 0 \\
$\mu_{1} \neq \mu_{2}, \sum_{1}=\sum_{2}$ & 8.42 & 7.81 & 3 & 0.0381 \\
$\mu_{1}=\mu_{2}, \sum_{1} \neq \sum_{2}$ & 17.72 & 5.99 & 2 & 0.0001 \\
\hline
\end{tabular}

These results can be interpreted as follows. The sources of mineral element at the rural site and at the kerbside site may differ. Moreover, the mechanism of accumulation and dispersion at the two sites may be also different (e.g., long range transport, dust resuspension and traffic-related processes). The combination of possibly different sources of mineral elements and diverse mechanism of accumulation/dispersion can concur to determine a different chemical composition and size distribution of the mineral matter contained in the PM.

In order to evaluate the nature of the difference between the mineral element concentrations of PM of kerbside and rural site, the perturbation difference is calculated between the perturbation centres related kerbside and rural site compositional dataset. The perturbation centre for kerbside site

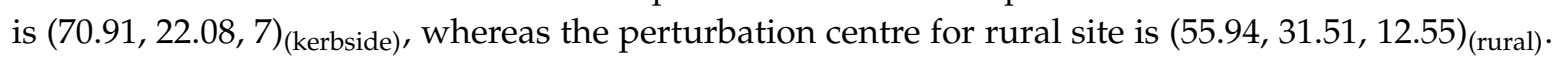
The perturbation difference is $(50.17,27.74,22.09)_{\text {(kerbside)-(rural) }}$ suggesting that the relative difference between these two sites is mainly in the coarse size fraction of the considered set of mineral elements. This may be a result of the resuspended mineral matter due to road traffic, which contributes to higher concentrations in the coarse size fraction at the kerbside site [61]. 


\section{Conclusions}

The statistical methods used for the analysis of compositional data allow for statistically validating either differences or similarities between the investigated datasets of the related environmental sites. These differences or similarities can be associated to both the kind of involved mineral sources and possible mechanisms of addition and/or subtraction of materials that influences the behavior of the characteristic environmental sites.

Results highlight that the datasets of kerbside site and background site have different centers and equal covariance structures. The mineral elements of PM of these two sites are compositionally equivalent. Though the two distinct centres indicate that mineral elements have different distribution. This can be related to possible different mechanisms of accumulation and/or dispersion of PM at the two sites. At the kerbside, the traffic in combination narrow streets and multi-floor building determines local characteristic conditions, which lead to higher tracer concentrations of the coarse size fraction.

The datasets of kerbside site and the rural site have different centers and covariance structures. The mineral elements of PM of these two sites are different for composition and size distribution. These two sites have different sources of mineral elements. Furthermore, the mechanism of accumulation and/or dispersion at the two sites may also be different. The combination of different sources and diverse mechanisms of accumulation and/or dispersion can concur to determine a different chemical composition and size distribution of the mineral elements of PM.

The compositional analysis applied to mineral element concentrations of $\mathrm{PM}_{10}, \mathrm{PM}_{2.5}$ and $\mathrm{PM}_{1}$ simultaneous measurements is a technique that can be used to study environmental sites interested by different sources of mineral matter.

Author Contributions: A.S. provided the idea and designed the study. A.S., R.C., G.P. and V.S. illustrated the figures and wrote the manuscript.

Conflicts of Interest: The authors declare no conflict of interest.

\section{References}

1. Anderson, J.O.; Thundiyil, J.G.; Stolbach, A. Clearing the air: A review of the effects of particulate matter air pollution on human health. J. Med. Toxicol. 2012, 8, 166-175. [CrossRef] [PubMed]

2. Janssen, N.A.H.; World Health Organization. Health Effects of Black Carbon; World Health Organization, Regional Office for Europe: Copenhagen, Denmark, 2012; ISBN 978-92-890-0265-3.

3. WHO (World Health Organization). Air Quality Guidelines: Global Update 2005: Particulate Matter, Ozone, Nitrogen Dioxide, and Sulfur Dioxide; World Health Organization, Regional Office for Europe: Geneva, Switzerland, 2006.

4. Kelly, F.J.; Fussell, J.C. Size, source and chemical composition as determinants of toxicity attributable to ambient particulate matter. Atmos. Environ. 2012, 60, 504-526. [CrossRef]

5. Heyder, J. Deposition of Inhaled Particles in the Human Respiratory Tract and Consequences for Regional Targeting in Respiratory Drug Delivery. Proc. Am. Thorac. Soc. 2004, 1, 315-320. [CrossRef] [PubMed]

6. Pope, C.A., III; Dockery, D.W. Health effects of fine particulate air pollution: Lines that connect. J. Air Waste Manag. Assoc. 2006, 56, 709-742. [CrossRef] [PubMed]

7. Caggiano, R.; D'Emilio, M.; Macchiato, M.; Ragosta, M. Experimental and statistical investigations on atmospheric heavy metals concentrations in an industrial area of Southern Italy. Nuovo Cimento C 2001, 24, 391-406.

8. Stocker, T.F.; Qin, D.; Plattner, G.K.; Tignor, M.M.; Allen, S.K.; Boschung, J.; Nauels, A.; Xia, Y.; Bex, V.; Midgley, P.M. Climate Change 2013: The Physical Science Basis. Contribution of Working Group I to the Fifth Assessment Report of IPCC the Intergovernmental Panel on Climate Change; Cambridge University Press: Cambridge, UK, 2014; ISBN 978-1-107-66182-0.

9. Prospero, J.M.; Charlson, R.J.; Mohnen, V.; Jaenicke, R.; Delany, A.C.; Moyers, J.; Rahn, K. The atmospheric aerosol system: An overview. Rev. Geophys. 1983, 21, 1607-1629. [CrossRef]

10. Haywood, J.; Boucher, O. Estimates of the direct and indirect radiative forcing due to tropospheric aerosols: A review. Rev. Geophys. 2000, 38, 513-543. [CrossRef] 
11. Prospero, J.M. African dust: Its large-scale transport over the Atlantic Ocean and its impact on the Mediterranean region. In Regional Climate Variability and Its Impacts in The Mediterranean Area; Springer: Dordrecht, The Netherlands, 2007; pp. 15-38. ISBN 978-1-4020-6429-6.

12. Putaud, J.P.; Van Dingenen, R.; Alastuey, A.; Bauer, H.; Birmili, W.; Cyrys, J.; Flentje, H.; Fuzzi, S.; Gehrig, R.; Hansson, H.C.; et al. A European aerosol phenomenology-3: Physical and chemical characteristics of particulate matter from 60 rural, urban, and kerbside sites across Europe. Atmos. Environ. 2010, 44, 1308-1320. [CrossRef]

13. Viana, M.; Kuhlbusch, T.A.J.; Querol, X.; Alastuey, A.; Harrison, R.M.; Hopke, P.K.; Winiwarter, W.; Vallius, M.; Szidat, S.; Prévôt, A.S.H.; et al. Source apportionment of particulate matter in Europe: A review of methods and results. J. Aerosol Sci. 2008, 39, 827-849. [CrossRef]

14. Thorpe, A.; Harrison, R.M. Sources and properties of non-exhaust particulate matter from road traffic: A review. Sci. Total Environ. 2008, 400, 270-282. [CrossRef] [PubMed]

15. Pant, P.; Harrison, R.M. Estimation of the contribution of road traffic emissions to particulate matter concentrations from field measurements: A review. Atmos. Environ. 2013, 77, 78-97. [CrossRef]

16. Van Dingenen, R.; Raes, F.; Putaud, J.P.; Baltensperger, U.; Charron, A.; Facchini, M.C.; Decesari, S.; Fuzzi, S.; Gehrig, R.; Hansson, H.C.; et al. European aerosol phenomenology-1: Physical characteristics of particulate matter at kerbside, urban, rural and background sites in Europe. Atmos. Environ. 2004, 38, 2561-2577. [CrossRef]

17. Colbeck, I. Environmental Chemistry of Aerosols; Blackwell Publishing Ltd.: Oxford, UK, 2008; ISBN 9781405139199.

18. Liu, Y.; Zhang, S.; Fan, Q.; Wu, D.; Chan, P.; Wang, X.; Fan, S.; Feng, Y.; Hong, Y. Accessing the Impact of Sea-Salt Emissions on Aerosol Chemical Formation and Deposition over Pearl River Delta, China. Aerosol Air Qual. Res. 2015, 15, 2232-2245. [CrossRef]

19. Caggiano, R.; Macchiato, M.; Trippetta, S. Levels, chemical composition and sources of fine aerosol particles $\left(\mathrm{PM}_{1}\right)$ in an area of the Mediterranean basin. Sci. Total Environ. 2010, 408, 884-895. [CrossRef] [PubMed]

20. Chakraborty, A.; Gupta, T. Chemical characterization and source apportionment of submicron (PM1) aerosol in Kanpur region, India. Aerosol Air Qual. Res. 2010, 10, 433-445. [CrossRef]

21. Margiotta, S.; Lettino, A.; Speranza, A.; Summa, V. PM 1 geochemical and mineralogical characterization using SEM-EDX to identify particle origin-Agri Valley pilot area (Basilicata, southern Italy). Nat. Hazards Earth Syst. Sci. 2015, 15, 1551-1561. [CrossRef]

22. Rogula-Kozłowska, W.; Rogula-Kupiec, P.; Mathews, B.; Klejnowski, K. Effects of road traffic on the ambient concentrations of three PM fractions and their main components in a large Upper Silesian city. Ann. Wars. Univ. Life Sci.-SGGW Land Reclam. 2013, 45, 243-253. [CrossRef]

23. Matassoni, L.; Pratesi, G.; Centioli, D.; Cadoni, F.; Lucarelli, F.; Nava, S.; Malesani, P. Saharan dust contribution to $\mathrm{PM}_{10}, \mathrm{PM}_{2.5}$ and $\mathrm{PM}_{1}$ in urban and suburban areas of Rome: A comparison between single-particle SEM-EDS analysis and whole-sample PIXE analysis. J. Environ. Monit. 2011, 13, 732-742. [CrossRef] [PubMed]

24. Makkonen, U.; Hellén, H.; Anttila, P.; Ferm, M. Size distribution and chemical composition of airborne particles in south-eastern Finland during different seasons and wildfire episodes in 2006. Sci. Total Environ. 2010, 408, 644-651. [CrossRef] [PubMed]

25. Yin, J.; Harrison, R.M. Pragmatic mass closure study for $\mathrm{PM}_{1.0}, \mathrm{PM}_{2.5}$ and $\mathrm{PM}_{10}$ at roadside, urban background and rural sites. Atmos. Environ. 2008, 42, 980-988. [CrossRef]

26. Pérez, N.; Pey, J.; Querol, X.; Alastuey, A.; López, J.M.; Viana, M. Partitioning of major and trace components in $\mathrm{PM}_{10}-\mathrm{PM}_{2.5}-\mathrm{PM}_{1}$ at an urban site in Southern Europe. Atmos. Environ. 2008, 42, 1677-1691. [CrossRef]

27. Chiari, M.; Del Carmine, P.; Lucarelli, F.; Marcazzan, G.; Nava, S.; Paperetti, L.; Prati, P.; Valli, G.; Vecchi, R.; Zucchiatti, A. Atmospheric aerosol characterisation by Ion Beam Analysis techniques: Recent improvements at the Van de Graaff laboratory in Florence. Nucl. Instrum. Methods Phys. Res. B 2004, 219, 166-170. [CrossRef]

28. Chiari, M.; Lucarelli, F.; Mazzei, F.; Nava, S.; Paperetti, L.; Prati, P.; Valli, G.; Vecchi, R. Characterization of airborne particulate matter in an industrial district near Florence by PIXE and PESA. X-ray Spectrom. 2005, 34, 323-329. [CrossRef]

29. Lim, S.; Lee, M.; Lee, G.; Kim, S.; Yoon, S.; Kang, K. Ionic and carbonaceous compositions of $\mathrm{PM}_{10}, \mathrm{PM}_{2.5}$ and $\mathrm{PM}_{1.0}$ at Gosan ABC Superstation and their ratios as source signature. Atmos. Chem. Phys. 2012, 12, 2007-2024. [CrossRef] 
30. Moreno, T.; Querol, X.; Alastuey, A.; Reche, C.; Cusack, M.; Amato, F.; Pandolfi, M.; Pey, J.; Richards, A.; Prévôt, A.S.H.; et al. Variations in time and space of trace metal aerosol concentrations in urban areas and their surroundings. Atmos. Chem. Phys. 2011, 11, 9415-9430. [CrossRef]

31. Theodosi, C.; Grivas, G.; Zarmpas, P.; Chaloulakou, A.; Mihalopoulos, N. Mass and chemical composition of size-segregated aerosols $\left(\mathrm{PM}_{1}, \mathrm{PM}_{2.5}, \mathrm{PM}_{10}\right)$ over Athens, Greece: Local versus regional sources. Atmos. Chem. Phys. 2011, 11, 11895-11911. [CrossRef]

32. Speranza, A.; Caggiano, R.; Margiotta, S.; Trippetta, S. A novel approach to comparing simultaneous size-segregated particulate matter (PM) concentration ratios by means of a dedicated triangular diagram using the Agri Valley PM measurements as an example. Nat. Hazards Earth Syst. Sci. 2014, 14, 2727-2733. [CrossRef]

33. Speranza, A.; Caggiano, R.; Margiotta, S.; Summa, V.; Trippetta, S. A clustering approach based on triangular diagram to study the seasonal variability of simultaneous measurements of $\mathrm{PM}_{10}, \mathrm{PM}_{2.5}$ and $\mathrm{PM}_{1}$ mass concentration ratios. Arab. J. Geosci. 2016, 9, 1-8. [CrossRef]

34. Aitchison, J. The statistical analysis of compositional data (with discussion). J. R. Stat. Soc. Ser. B Stat. Methodol. 1982, 44, 139-177.

35. Aitchison, J. The Statistical Analysis of Compositional Data; Chapman and Hall: London, UK, 1986; 416p, ISBN 0-412-28060-4.

36. Pawlowsky-Glahn, V.; Buccianti, A. Visualization and modeling of sub-populations of compositional data: Statistical methods illustrated by means of geochemical data from fumarolic fluids. Int. J. Earth Sci. 2002, 91, 357-368. [CrossRef]

37. Martín-Fernández, J.A.; Barceló-Vidal, C.; Pawlowsky-Glahn, V. Dealing with zeros and missing values in compositional datasets using nonparametric imputation. Math. Geol. 2003, 35, 253-278. [CrossRef]

38. Buccianti, A.; Pawlowsky-Glahn, V. Statistical evaluation of compositional changes in volcanic gas chemistry: A case study. Stoch. Environ. Res. Risk Assess. 2006, 21, 25-33. [CrossRef]

39. Pawlowsky-Glahn, V.; Buccianti, A. Compositional Data Analysis: Theory and Applications; John Wiley \& Sons: Chichester, UK, 2011; ISBN 9780470711354.

40. Buccianti, A.; Pawlowsky-Glahn, V. New perspectives on water chemistry and compositional data analysis. Math. Geol. 2005, 37, 703-727. [CrossRef]

41. Visser, S.; Slowik, J.G.; Furger, M.; Zotter, P.; Bukowiecki, N.; Dressler, R.; Flechsig, U.; Appel, K.; Green, D.C.; Tremper, A.H.; et al. Kerb and urban increment of highly time-resolved trace elements in $\mathrm{PM}_{10}, \mathrm{PM}_{2.5}$ and $\mathrm{PM}_{1.0}$ winter aerosol in London during ClearfLo 2012. Atmos. Chem. Phys. 2015, 15, 2367-2386. [CrossRef]

42. Putaud, J.P.; Van Dingenen, R.; Raes, F. Submicron aerosol mass balance at urban and semirural sites in the Milan area (Italy). JGR-Atmospheres 2002, 107, 8198. [CrossRef]

43. Putaud, J.P.; Raes, F.; Van Dingenen, R.; Brüggemann, E.; Facchini, M.C.; Decesari, S.; Fuzzi, S.; Gehrig, R.; Hüglin, C.; Laj, P.; et al. A European aerosol phenomenology-2: Chemical characteristics of particulate matter at kerbside, urban, rural and background sites in Europe. Atmos. Environ. 2004, 38, 2579-2595. [CrossRef]

44. Colbeck, I.; Nasir, Z.A.; Ahmad, S.; Ali, Z. Exposure to $\mathrm{PM}_{10}, \mathrm{PM}_{2.5}, \mathrm{PM}_{1}$ and carbon monoxide on roads in Lahore, Pakistan. Aerosol Air Qual. Res. 2011, 11, 689-695. [CrossRef]

45. Vallius, M.J.; Ruuskanen, J.; Mirme, A.; Pekkanen, J. Concentrations and estimated soot content of $\mathrm{PM}_{1}$, $\mathrm{PM}_{2.5}$, and $\mathrm{PM}_{10}$ in a subarctic urban atmosphere. Environ. Sci. Technol. 2000, 34, 1919-1925. [CrossRef]

46. Lundgren, D.A.; Hlaing, D.N.; Rich, T.A.; Marple, V.A. $\mathrm{PM}_{10} / \mathrm{PM}_{2.5} / \mathrm{PM}_{1}$ data from a trichotomous sampler. Aerosol Sci. Technol. 1996, 25, 353-357. [CrossRef]

47. Pawlowsky-Glahn, V.; Egozcue, J.J. Compositional data and their analysis: An introduction. In Compositional Data Analysis in the Geosciences: From Theory to Practice; Special Publications; Buccianti, A., Mateu-Figueras, G., Pawlowsky-Glahn, V., Eds.; Geological Society: London, UK, 2006; Volume 264, pp. 1-10.

48. Egozcue, J.J.; Pawlowsky-Glahn, V.; Mateu-Figueras, G.; Barceló-Vidal, C. Isometric logratio transformations for compositional data analysis. Math. Geol. 2003, 35, 279-300. [CrossRef]

49. Pawlowsky-Glahn, V.; Egozcue, J.J.; Tolosana Delgado, R. Lecture Notes on Compositional Data Analysis. 2007. Available online: http:/ / dugi-doc.udg.edu//handle/10256/297 (accessed on 8 February 2008).

50. Graham, D.J.; Midgley, N.G. TECHNICAL COMMUNICATION-Graphical Representation of Particle Shape using Triangular Diagrams: An Excel Spreadsheet Method. Earth Surf. Processes Landf. 2000, 25, 1473-1478. [CrossRef] 
51. Comas-Cufí, M.; Thió-Henestrosa, S. CoDaPack 2.0: A stand-alone, multi-platform compositional software. In Proceedings of the CoDaWork'11: 4th International Workshop on Compositional Data Analysis, Sant Feliu de Guíxols, Girona, Spain, 10-13 May 2011.

52. R Development Core Team R. A Language and Environment for Statistical Computing; R Foundation for Statistical Computing: Vienna, Austria, 2008; ISBN 3-900051-07-0.

53. Buccianti, A.; Pawlowsky-Glahn, V.; Barceló-Vidal, C.; Jarauta-Bragulat, E. Visualization and modeling of natural trends in ternary diagrams: A geochemical case study. In Proceedings of the IAMG, Trondheim, Norway, 6-11 August 1999; Volume 99, pp. 139-144.

54. Martín-Fernández, J.A.; Bren, M.; Barceló-Vidal, C.; Pawlowsky-Glahn, V. A measure of difference for compositional data based on measures of divergence. In Proceedings of the IAMG, Trondheim, Norway, 6-11 August 1999; Volume 99, pp. 211-216.

55. Von Eynatten, H.; Pawlowsky-Glahn, V.; Egozcue, J.J. Understanding perturbation on the simplex: A simple method to better visualize and interpret compositional data in ternary diagrams. Math. Geol. 2002, 34, 249-257. [CrossRef]

56. Aitchison, J.; Egozcue, J.J. Compositional data analysis: Where are we and where should we be heading? Math. Geol. 2005, 37, 829-850. [CrossRef]

57. Pawlowsky-Glahn, V.; Egozcue, J.J.; Tolosana-Delgado, R. Modeling and Analysis of Compositional Data; John Wiley \& Sons: Chichester, UK, 2015; ISBN 9781118443064.

58. Stephens, M.A. EDF statistics for goodness of fit and some comparisons. J. Am. Stat. Assoc. 1974, 69, 730-737. [CrossRef]

59. Aitchison, J. A Concise Guide to Compositional Data Analysis. In 2nd Compositional Data Analysis Workshop—CoDaWork'05; Universitat de Girona: Girona, Spain, 2005; Available online: http://ima. udg.edu/Activitats/CoDaWork05/A_concise_guide_to_compositional_data_analysis.pdf (accessed on 19 October 2015).

60. Harrison, R.M.; Yin, J.; Mark, D.; Stedman, J.; Appleby, R.S.; Booker, J.; Moorcroft, S. Studies of the coarse particle $(2.5-10 \mu \mathrm{m})$ component in UK urban atmospheres. Atmos. Environ. 2001, 35, 3667-3679. [CrossRef]

61. Jones, A.M.; Harrison, R.M. Assessment of natural components of $\mathrm{PM}_{10}$ at UK urban and rural sites. Atmos. Environ. 2006, 40, 7733-7741. [CrossRef] 